\title{
Long acting $\beta 2$-agonist and corticosteroid restore airway glandular cell function altered by bacterial supernatant
}

\author{
Jean-Marie Zahm ${ }^{1,3^{*}}$, Franck Delavoie ${ }^{1,2,3}$, Férial Toumi ${ }^{1}$, Béatrice Nawrocki-Raby ${ }^{1,3}$, Claire Kileztky ${ }^{1,3}$, Jean Michel ${ }^{2,3}$, \\ Gérard Balossier ${ }^{2,3}$, Malcolm Johnson $^{5}$, Christelle Coraux ${ }^{1,3}$, Philippe Birembaut ${ }^{1,3,4}$
}

\begin{abstract}
Background: Staphylococcus aureus releases virulence factors (VF) that may impair the innate protective functions of airway cells. The aim of this study was to determine whether a long-acting $\beta_{2}$ adrenergic receptor agonist (salmeterol hydroxynaphthoate, Sal) combined with a corticosteroid (fluticasone propionate, FP) was able to regulate ion content and cytokine expression by airway glandular cells after exposure to $S$. aureus supernatant.

Methods: A human airway glandular cell line was incubated with $S$. aureus supernatant for $1 \mathrm{~h}$ and then treated with the combination Sal/FP for $4 \mathrm{~h}$. The expression of actin and CFTR proteins was analyzed by immunofluorescence. Videomicroscopy was used to evaluate chloride secretion and X-ray microanalysis to measure the intracellular ion and water content. The pro-inflammatory cytokine expression was assessed by RT-PCR and ELISA.

Results: When the cells were incubated with S. aureus supernatant and then with Sal/FP, the cellular localisation of CFTR was apical compared to the cytoplasmic localisation in cells incubated with S. aureus supernatant alone. The incubation of airway epithelial cells with S. aureus supernatant reduced by $66 \%$ the chloride efflux that was fully restored by Sal/FP treatment. We also observed that Sal/FP treatment induced the restoration of ion $(\mathrm{Cl}$ and $\mathrm{S})$ and water content within the intracellular secretory granules of airway glandular cells and reduced the bacterial supernatant-dependent increase of pro-inflammatory cytokines IL8 and TNF $\alpha$.

Conclusions: Our results demonstrate that treatment with the combination of a corticosteroid and a long-acting $\beta_{2}$ adrenergic receptor agonist after bacterial infection restores the airway glandular cell function. Abnormal mucus induced by defective ion transport during pulmonary infection could benefit from treatment with a combination of $\beta_{2}$ adrenergic receptor agonist and glucocorticoid.
\end{abstract}

\section{Background}

The epithelial lining of the airways provides an efficient barrier against microorganisms through interdependent functions including mucociliary clearance, homeostasis of ion and water transport, biochemical responses and acts as a cellular barrier function by means of intercellular junctions. These functions are fundamental to the maintenance of the defence and the integrity of the airway epithelium which may be disturbed after any infectious insult in diseases such as chronic obstructive pulmonary disease (COPD) or cystic fibrosis (CF).

\footnotetext{
* Correspondence: jm.zahm@univ-reims.fr
} ${ }^{1}$ INSERM, U903, Reims, F-51092, France
Staphylococcus aureus (S. aureus) is one of the most common gram-positive bacteria involved in airway infections, either primary or subsequent to viral diseases [1]. $S$. aureus is also a major cause of hospital acquired lower respiratory tract infections and is often implicated in early infectious airway disease in CF patients [2]. $S$. aureus expresses several potential virulence factors (VF) that may induce airway epithelium injury and impair the epithelial wound/repair process [3]. Remodeling that occurs following injury may considerably disturb the innate protective function of the respiratory epithelium. Abnormal expression and distribution of CFTR protein is not only caused by mutations of the CF gene but is 
also observed in non-CF inflamed and/or remodeled airway tissues [4] and may thereby induce alteration of the airway mucus mainly produced by the airway glandular cells [5,6]. Abnormal mucus production is the hallmark of chronic inflammatory airway diseases such as asthma, chronic bronchitis, and CF $[7,8]$. Sputum has altered macromolecular composition and biophysical properties which vary with disease, but unifying features are failure of mucociliary transport resulting in airway obstruction [9]. Protection of the airway epithelium or restoration of its function requires factors that prevent or reverse cellular damage caused by bacterial VF. There is already evidence of enhanced respiratory cytoprotection against bacterial infection when airway epithelial cells are preincubated with a long-acting beta- 2 adrenergic receptor $\left(\beta_{2} A R\right)$ agonist [10]. Furthermore, the increased CFTR expression associated with $\beta_{2} \mathrm{AR}$ stimulation may have other beneficial effects on ion and water transport, protein expression and differentiation [11]. We have also shown that pre-treatment with the combination of a long-acting $\beta_{2} \mathrm{AR}$ (salmeterol hydroxynaphthoate, Sal) and a corticosteroid (fluticasone propionate, FP) induces a downregulation of $S$. aureus-induced airway epithelial inflammation, particularly by modulating the expression of cytokines such as IL-6, IL-8 or TNFa [12].

Although previous studies have shown a preventive role of combined $\beta_{2} \mathrm{AR}$ agonist/corticosteroid (Sal/FP) on COPD exacerbations [13] and bacterial VF-induced alterations in human airway epithelial cells, the role of this combination used as a treatment to correct the deleterious effect of bacterial VF is currently unknown. In addition, whether bacterial infection of airway epithelial cells may induce alterations in ion transport and loss of epithelial electrolyte homeostasis has not been extensively investigated. Therefore, the aim of this study was to determine whether Sal/FP combination is able to restore intracellular ion and water content and inflammatory cytokine expression previously altered by $S$ aureus supernatant. The experiments were performed on an airway glandular cell line since these cells are the main source of airway mucus and associated secretion products (ions, mucins, cytokines,) [6]. In addition these cells are characterized by numerous intracellular secretory granules which can be analyzed in terms of ion concentration. Since $S$. aureus VF have been demonstrated to be able to disrupt actin cables [14] and that this disruption may lead to CFTR delocalisation [15], we also investigated the effect of Sal/FP treatment on actin and CFTR cellular localisation. The use of Sal/FP combination is based upon experiments by which tissues incubated with low concentrations of Sal/FP would support a synergistic action between the two compounds and that the higher concentrations showed no added benefit with respect to mucosal damage compared to either agent alone at the same concentration [16].

Our results demonstrate that $S$. aureus VF produced during airway infection induce alterations of ion and water content in airway secretory granules, which may be at the onset of decreased mucociliary clearance frequently observed during pulmonary infection exacerbations [17]. Treatment with a corticosteroid combined with a $\beta_{2} A R$ agonist is able to correct these anomalies and may be helpful for restoring normal cytoprotective properties of the airway epithelium.

\section{Methods}

\section{Preparation of bacterial supernatant}

$S$. aureus strain 8325-4, a wild-type laboratory strain (fibronectin-binding protein (FnBP) $\mathrm{A}^{+}$and $\mathrm{FnBPB}^{+}$, NTC 8325 cured of prophages), was a generous gift from T.J. Foster (Department of Microbiology, Trinity College, Dublin, Ireland). Bacterial supernatant was prepared by growing bacteria in trypticase soy broth (TSB, AES Laboratoire, Bruz, France) for $16-18 \mathrm{~h}$ at $37^{\circ} \mathrm{C}$ under agitation $(120 \mathrm{rpm})$. Supernatant of $5 \times 10^{8} \mathrm{cfu} /$ $\mathrm{ml}$ was obtained by centrifugation at $960 \mathrm{~g}$ for $10 \mathrm{~min}$ at $4^{\circ} \mathrm{C}$, then filtration through a $0.2 \mu \mathrm{m}$ filter (Pall Gelman Science, Ann Arbor, Michigan). The supernatant containing S. aureus soluble VF was diluted to $2 \%, 10 \%$ or $20 \%$ in Dulbecco's modified Eagle's medium (DMEM)/F-12 (Sigma Aldrich, St Louis, MO). TSB was used as control at 2, 10 or 20\% in DMEM/F-12.

\section{Preparation of salmeterol hydroxynaphthoate and} fluticasone propionate

Salmeterol hydroxynaphthoate (Sal), provided by GlaxoSmithKline (Uxbridge, UK), was dissolved in a minimum amount of glacial acetic acid $(30 \mu \mathrm{l})$, then diluted to a concentration of $2 \times 10^{-4} \mathrm{M}$ in phosphate-buffered saline (PBS; Gibco, Invitrogen, Paisley, UK) and kept at $-20^{\circ} \mathrm{C}$. The solution was buffered to a $\mathrm{pH}$ of 7.4 . The stock solution was used at a final concentration of $2 \times$ $10^{-7} \mathrm{M}$ in DMEM/F-12 previously defined as optimal for inducing airway epithelial cytoprotection [18].

A stock solution of fluticasone propionate (FP) provided by GlaxoSmithKline was prepared $\left(1 \times 10^{-5} \mathrm{M}\right)$ in $1 \mathrm{mM}$ ethanol (Merck Eurolab, Darmstadt, Germany). FP was diluted with DMEM/F-12 medium to a final concentration of $1 \times 10^{-8} \mathrm{M}$, a concentration previously found to have anti-inflammatory effects in bronchial epithelial cells [19].

\section{Cell culture and experimental procedure}

The transformed human tracheal glandular cell line MM-39 [20] was grown in DMEM/F-12 supplemented with $1 \%$ Ultroser $\mathrm{G}$ serum substitute (Biosepra, Villeneuve-la-Garenne, France), glucose (10 g/l), sodium pyruvate $(0.33 \mathrm{~g} / \mathrm{l})$, penicillin $(100 \mathrm{IU} / \mathrm{ml})$, streptomycin $(100 \mu \mathrm{g} / \mathrm{ml})$ and amphotericin $\mathrm{B}(2 \mu \mathrm{g} / \mathrm{ml})$ on porous 
membranes (12-well Transwell Clear, Costar, France) coated with type I collagen $(50 \mu \mathrm{g} / \mathrm{ml})$ prepared as previously described [21] and was cultured at $37^{\circ} \mathrm{C}$ under a $5 \% \mathrm{CO}_{2}$ atmosphere. In a first set of experiments to determine the effect of $S$. aureus supernatant on cell death, cells were incubated with $2 \%, 10 \%$ or $20 \%$ of $S$. aureus supernatant or with medium alone (DMEM/F-12 supplemented with $2 \%, 10 \%$ or $20 \%$ of TSB) for 5 hours. In the subsequent experiments, cells were incubated with either control medium alone (DMEM/F-12 supplemented with $2 \%$ of TSB), or in presence of $S$. aureus supernatant $(2 \%)$ for $1 \mathrm{~h}$, then treated with Sal/FP $(2 \times$ $10^{-7} \mathrm{M}$ and $1 \times 10^{-8} \mathrm{M}$, respectively) or vehicles (glacial acetic acid and ethanol) for $4 \mathrm{~h}$.

\section{Assessment of cell viability}

A fluorescence staining method using propidium iodide and syto9 (Molecular Probes, Eugene, OR) was used to study the cell death/viability of airway epithelial cells incubated with $S$. aureus supernatant. Propidium iodide only penetrates into cells with damaged membranes, staining the cells in red, whereas syto9 penetrates into all cells, staining them in green. Briefly, at cell culture confluence, medium was removed from the culture plates, and cells were washed three times with sterile PBS and incubated with $2 \%, 10 \%$ or $20 \%$ of $S$. aureus supernatant or TSB, propidium iodide $(1 \mu \mathrm{l} / \mathrm{ml})$ and syto9 $(1 \mu \mathrm{l} / \mathrm{ml})$. Culture dishes were placed on the stage of an inverted microscope (Axiovert $200 \mathrm{M}$; Zeiss, Le Pecq, France) equipped with an environmental chamber $\left(37^{\circ} \mathrm{C}, 5 \% \mathrm{CO}_{2}, 100 \%\right.$ relative humidity) and with a charge-coupled device video camera (Coolsnap Fx; Roper Scientific, Tucson, AZ). Using Metamorph (Universal Imaging, Downingtown, PA) software, we recorded time-lapse fluorescent images every hour for 5 $h$. Variations of the fluorescence intensity of propidium iodide were related to the variation of the number of dead cells. To assess the cell viability, airway glandular cells were seeded on a 96 well microplate. At confluence, they were incubated for $5 \mathrm{~h}$ with $2 \%, 10 \%$ or $20 \%$ of $S$. aureus supernatant or TSB in culture medium and then for 1 hour with $1 \mathrm{mg} / \mathrm{ml}$ methylthiazolyldiphenyltetrazolium bromide (MTT, Sigma Aldrich, St Louis, $\mathrm{MO})$. The dye was extracted with propanol-2 and the OD at $560 \mathrm{~nm}$ was read in a Xenius spectrophotometer (Safas, Monaco).

\section{Western blot analysis}

For membrane extract, $2 \% \mathrm{~S}$. aureus supernatant-treated or $2 \%$ TSB-treated cells were disrupted mechanically in cold Tris buffer $(50 \mathrm{mM}$ Tris-HCL pH 7.5, $1 \mathrm{mM}$ EDTA with complete protease inhibitor mixture (Roche Applied Science) for $15 \mathrm{~min}$ on ice and precipitated at $4^{\circ} \mathrm{C}$ overnight with $4 \%(\mathrm{v} / \mathrm{v})$ trichloroacetic acid. After centrifugation $\left(2500 \mathrm{~g}\right.$ for $10 \mathrm{~min}$ at $4^{\circ} \mathrm{C}$ ), the pellet was dissolved in $100 \mu \mathrm{l}$ RIPA buffer. Six $\mu \mathrm{g}$ of protein extracts were separated by electrophoresis on 7.5\% SDSpolyacrylamide gels and electroblotted to PVDF membranes using $100 \mathrm{~V}$ for $1 \mathrm{~h}$ at $4^{\circ} \mathrm{C}$. Membranes were incubated for $1 \mathrm{~h}$ in a blocking buffer containing 5\% non-fat dry milk in PBS with $0.1 \%$ Tween 20, then overnight with mouse anti-CFTR antibody (clone 24-1, 1:1000, R\&D Systems, Lille, France) or with rabbit antiactin antibody (A2066, 1:1000, Sigma-Aldrich, St Louis MO, USA) and finally with horseradish peroxidase (HRP)-conjugated anti-mouse immunoglobulin antibody (1:1,000; DakoCytomation, Glostrup, Denmark) or horseradish peroxidase (HRP)-conjugated anti-rabbit immunoglobulin antibody (1:1000, DakoCytomation). Blots were revealed by using an ECL+ kit (GE Healthcare, Little Chalfont, UK) and analyzed by densitometry with a Fuji Las-1000 (Raytest, Courbevoie, France).

\section{Actin and CFTR co-localisation by immunocytochemistry}

To detect actin by immunofluorescence, we used an affinity isolated antigen specific antibody obtained from rabbit anti-actin antiserum by immuno-specific purification (A2066, 1:25, Sigma-Aldrich, St Louis MO, USA) [22]. CFTR was detected using the MAB25031 antibody (clone 24-1, diluted 1:100, R\&D Systems, Lille, France) which is recommended by the European Working Group on CFTR expression [23]. MM-39 cells were seeded onto glass slides coated with type I collagen (50 $\mu \mathrm{g} / \mathrm{ml}$ ) and fixed at confluence with cold methanol for $10 \mathrm{~min}$ at $-20^{\circ} \mathrm{C}$. After sequential incubation with the anti-actin antibody, Alexa Fluor 594-conjugated goat anti-rabbit antibody (1:200, Molecular Probes, Eugene, OR), anti-CFTR antibody and Alexa Fluor 488-conjugated goat anti-mouse antibody (1:200, Molecular Probes), cells were incubated for $10 \mathrm{~min}$ with DAPI (4',6'-diamino-2-phenylindole, $200 \mathrm{ng} / \mathrm{ml}$, Sigma Aldrich) for nuclear staining, then mounted with Aquapolymount antifading solution (Polysciences, Warrington, Pennsylvania) onto glass slides. Slides were observed under an AxioImager fluorescence microscope (Zeiss, Le Pecq, France) equipped with an apotome device (Zeiss). Images were recorded with a CCD video camera (Coolsnap, Roper Scientific, Tucson, AZ) at 40 successive $\mathrm{z}$ levels $(0.25 \mu \mathrm{m}$ between each $\mathrm{z}$ level $)$ at $\times 63$ magnification. The Metamorph software (Universal Imaging, Sunnyvale, CA) was used to quantify regions of overlap of actin and CFTR fluorescence. Both source images were thresholded and the areas of overlap were determined by calculating the number of pixels of actin staining overlaping with CFTR staining. Data were expressed in percentage of pixel overlap.

\section{Measurement of chloride efflux}

The chloride efflux in airway epithelial cells was evaluated by videomicroscopy using the halide-quenched dye 6-methoxy-N-(3-sulfopropyl) quinolinium probe (SPQ, Molecular Probes) in a chloride buffer solution (130 
$\mathrm{mM} \mathrm{NaCl}$, $2.4 \mathrm{mM} \mathrm{K}_{2} \mathrm{HPO}_{4}, 10 \mathrm{mM}$ D-glucose, $1 \mathrm{mM}$ $\mathrm{CaSO}_{4}, 1 \mathrm{mM} \mathrm{MgSO}$, and $10 \mathrm{mM}$ Hepes) made hypotonic by adding an equivalent volume of water, as previously described [24]. Thereafter, the hypotonic chloride buffer was replaced by an isotonic chloride buffer for 15 minutes and then by a nitrate buffer in which the $\mathrm{NaCl}$ was replaced by $130 \mathrm{mM}$ of $\mathrm{NaNO}_{3}$. The culture dish was placed on the heated stage of an inverted microscope (TE 300; Nikon, Champigny sur Marne, France). After 30 seconds, amiloride $(10 \mu \mathrm{M})$, and 1.5 minutes later, forskolin $(25 \mu \mathrm{M})$, were added to the nitrate buffer. Throughout the experimental process, fluorescence images $\lambda_{\text {ex }}$ at $365 \mathrm{~nm}$ and $\lambda_{\text {em }}$ at $395 \mathrm{~nm}$ ) were recorded every 15 seconds using a Micromax CCD camera and the Metafluor software (Roper Scientific, Evry, France). Chloride efflux was calculated by measuring the variations in SPQ fluorescence $(\Delta F / \Delta t)$ over a $1.5 \mathrm{~min}$ incubation period after the addition of forskolin, and expressed as arbitrary units. In some experiments, the cells were incubated for $1 \mathrm{~h}$ in serum-free culture medium containing $5 \mu \mathrm{M} \mathrm{CFTR}_{\text {inh-172 }}$ (Sigma Aldrich), which is a thiazolidinone CFTR inhibitor [25].

\section{Ion and water content analysis}

Ion and water content was determined using electron probe X-ray microanalysis and a quantitative dark field intensity technique with a scanning transmission electron microscope (STEM CM30, Philips) for measuring the in situ ion and water content in the cytoplasm and in the secretory granules of entire cryofixed cells [26]. In practice, the cryosection of cells irradiated by an electron beam emits an X-ray signal. The emission spectrum corresponds to the counting of X-rays emitted according to their energy. The intensity ratio specific peak/background allows the measurement of the concentrations of all the elements detected in the spectrum. To obtain the exact value of the mass concentrations $(\mathrm{mmol} / \mathrm{kg}$ dry weight) of the elements of interest $(\mathrm{Na}$, $\mathrm{Mg}, \mathrm{S}, \mathrm{Cl}$ and $\mathrm{K}$ ), we measured under the same experimental conditions, the specific peak/background ratio of the elements compared with standard samples of known mass concentrations. The mass concentrations in $\mathrm{mmol} /$ $\mathrm{kg}$ of dry matter $(\mathrm{Cd})$ can be converted into $\mathrm{mmol} / \mathrm{l}$ of water $\left(C_{h}\right)$ by using the equation $C_{h}=((100-L) / L) \times$ $\mathrm{Cd}$ where $\mathrm{L}$ is the percentage of water determined by quantitative dark field imaging. The water mass content was deduced from the complement to $100 \%$ of dry mass content measured on the dark field images. We developed an original method for intracellular water content quantification with high spatial resolution $(<30 \mathrm{~nm})$ based on dark field imaging. A hydrated cryosection contains a dry mass percentage $(\mathrm{M})$ and its water complement (L) with $\mathrm{L}+\mathrm{M}=100 \%$. During biological sample freeze-drying inside the microscope column, water (under amorphous ice sate) is sublimed and then the relative dark field intensity becomes directly proportional to the percentage of sample dry mass. By image processing, we obtained a parametric image in which the grey levels were proportional to the mass water content (L). The intracellular water content (L) was calculated by comparison with relative dark field intensities of standard samples with known water content. According to the different experimental conditions, 36 to 65 secretory granules from 14 to 21 cells were analyzed. Prior to the quantitative X-ray microanalysis, we showed that the $\mathrm{K} / \mathrm{Na}$ ratio in the nucleus and in the cytoplasm was higher than 5 , which is a characteristic of living confluent cells [27].

\section{Cytokine secretion measurement}

Culture medium was collected and cytokine protein levels were determined using sandwich enzyme-linked immunoabsorbent assays (ELISA) for IL-8, IL-6 and high-sensitivity TNF $\alpha$ detection (R\&D Systems, Minneapolis, MN) following the manufacturer's instructions. Results are expressed as $\mathrm{pg} / \mathrm{ml}$.

\section{RNA extraction and Reverse Transcriptase-Polymerase} Chain Reaction analysis

RNA extraction of cells was performed with the High Pure RNA isolation kit (Roche Diagnostics GmBH, Mannheim, Germany) following the manufacturer's instructions. Reverse transcriptase (RT)-polymerase chain reaction (PCR) was performed with $10 \mathrm{ng}$ of total RNA using the GeneAmp Thermostable RNA PCR Kit (Perkin Elmer, Foster City, CA) and three pairs of oligonucleotides (Eurogentec, Seraing, Belgium). Forward and reverse primers for human IL-8, TNF- $\alpha$, and $28 \mathrm{~S}$ were designed as follows: IL-8 primers, forward 5'-GCCAAGGAGTGCTAAAGAACTTAG-3', reverse 5'-GAATTCTCAGCCCTCTTCAAAAAC-3'; TNF- $\alpha$ primers, forward 5'-CAGCCTCTTCTCCTTCCTGA-3', reverse 5'TGAGGTACAGGCCCTCTGAT-3' and $28 \mathrm{~S}$ primers, forward 5'-GTTCACCCACTAATAGGGAACGTGA-3', reverse 5'-GGATTCTGACTTAGAGGCGTTCAGT-3'. For the IL-8 PCR, an initial denaturation at $95^{\circ} \mathrm{C}$ for 2 min was followed by 25 amplification cycles (denaturation at $94^{\circ} \mathrm{C}$ for $15 \mathrm{sec}$, annealing at $60^{\circ} \mathrm{C}$ for $20 \mathrm{sec}$, and elongation at $72^{\circ} \mathrm{C}$ for $10 \mathrm{sec}$ ) and a final 2-min elongation at $72^{\circ} \mathrm{C}$. For the TNF- $\alpha$ PCR, the conditions were as follows: initial denaturation $\left(94^{\circ} \mathrm{C}, 2 \mathrm{~min}\right), 29$ amplification cycles (denaturation $94^{\circ} \mathrm{C}, 30 \mathrm{sec}$, annealing $59^{\circ} \mathrm{C}, 30 \mathrm{sec}$, and elongation $72^{\circ} \mathrm{C}, 30 \mathrm{sec}$ ) and final elongation $\left(72^{\circ} \mathrm{C}, 7 \mathrm{~min}\right)$. For the $28 \mathrm{~S} \mathrm{PCR}$, the conditions were as follows: initial denaturation $\left(95^{\circ} \mathrm{C}, 2 \mathrm{~min}\right)$, 13 amplification cycles (denaturation $94^{\circ} \mathrm{C}, 15 \mathrm{sec}$, annealing $66^{\circ} \mathrm{C}, 20 \mathrm{sec}$, and elongation $72^{\circ} \mathrm{C}, 10 \mathrm{sec}$ ), final elongation $\left(72^{\circ} \mathrm{C}, 2 \mathrm{~min}\right)$. The expected sizes of the transcripts of IL-8, TNF- $\alpha$ and $28 \mathrm{~S}$ were $222 \mathrm{bp}, 302$ bp and $212 \mathrm{bp}$, respectively. RT-PCR products were separated by acrylamide gel electrophoresis, stained with 
SYBR gold (Molecular Probes) and visualized by fluorimetric scanning (Fuji, LAS-1000, Raytest, France). The IL- 8 and TNF- $\alpha$ mRNA values were normalized to $28 \mathrm{~S}$ mRNA values. Results represent the mean \pm SD of eight independent experiments performed in duplicate.

\section{Data analysis}

Values were reported as mean \pm SEM. Non parametric Man and Whitney test and one-way Kruskall-Wallis test were used for comparisons between groups and differences were considered to be statistically significant with $P$ values less than 0.05 .

\section{Results}

\section{Effect of $S$. aureus supernatant on cell viability}

To assess the effect of $S$. aureus supernatant on cell viability, airway glandular cells were incubated with increasing concentrations of bacterial supernatant. Cell death was evaluated by using the propidium iodide fluorescent probe and cell viability by using the MTT assay. Figure 1A displays fluorescent images recorded after 5 hours of incubation with S. aureus supernatant. In control condition or in presence of $2 \%$ S. aureus supernatant, a limited number of cells showed a red nucleus staining characteristic of dead cells, whereas the number of dead cells dramatically increased in presence of $10 \%$ or $20 \%$ of $S$. aureus supernatant. A typical timedependent increase in red fluorescent staining is displayed in figure $1 \mathrm{~B}$, showing a similar curve pattern for the control experiment and the experiment in presence of $2 \%$ S. aureus supernatant. The comparison of the grey levels of the red fluorescence after $5 \mathrm{~h}$ of incubation with $S$. aureus supernatants is shown in figure 1C. A significant increase in fluorescence, reflecting the increase in cell death, was observed when the cells were incubated with $10 \%$ or $20 \%$ of S. aureus supernatant (p $<0.01$ ). In parallel, using the MTT technique, we quantified by OD measurement the number of living cells and observed that this number significantly $(\mathrm{p}<0.01)$ decreased in presence of 10 or $20 \%$ of $S$. aureus supernatants (figure 1C). From these data we can therefore conclude that the incubation for $5 \mathrm{~h}$ with $2 \%$ S. aureus supernatant did not significantly altered the cellular viability.

\section{Effect of $S$. aureus supernatant on CFTR expression}

Immunofluorescence and Western blotting were used to test the effect of $S$. aureus supernatant on CFTR expression at the cell membrane level. As shown in figure 2, we observed that the incubation of airway glandular cells with $2 \% \mathrm{~S}$. aureus supernatant reduced the expression level of CFTR at the cell membrane, indicating a delocalisation of this protein from the apical membrane. CFTR localisation was assessed by using immunofluorescence imaging at different $\mathrm{z}$ levels. Figure $2 \mathrm{~A}$ and $2 \mathrm{~B}$ shows the cellular distribution of CFTR in a lateral image obtained from different $\mathrm{z}$ levels. In the control cells (figure 2A) we observed a high staining at the apical pole of cells. In the cells treated with $2 \%$ S. aureus supernatant, we observed the loss of the CFTR staining at the apical pole and a more diffuse cytoplasmic staining. We performed complementary western blotting analysis on cell membrane extracts (figure $2 \mathrm{C}$ ) and measured a significant $(\mathrm{p}<0.05)$ decrease in CFTR expression when the cells were incubated with $2 \%$ S. aureus supernatant (figure 2D).

\section{Actin and CFTR co-localisation is restored by Sal/FP treatment}

Since it has been previously demonstrated that CFTR may directly bind actin and that this interaction may affect the functional properties of this channel protein [28], we aimed at analyzing the effect of $S$. aureus supernatant on actin and CFTR relationship. For that purpose, we examined the co-localisation of these proteins by immunofluorescence. The pattern of staining of CFTR (green staining) and actin (red staining) was essentially apical in control cells (figure 3A). The incubation of cells with Sal/FP enhanced the apical localisation of CFTR (figure 3B). In contrast, incubation of cells with $2 \%$ S. aureus supernatant induced an alteration in the localisation of CFTR which appeared to be more cytoplasmic (figure 3C) as previously shown in figure 2 . Treatment of cells with Sal/FP restored CFTR and actin apical localisation (figure 3D). Quantification of the colocalisation of CFTR and actin (figure 3E) showed that $2 \%$ S. aureus supernatant decreased by $47 \%$ the co-localisation index compared with control cells, but the difference was not statistically significant. Interestingly, treatment with Sal/FP alone or after $S$. aureus supernatant incubation significantly enhanced the co-localisation of the 2 proteins compared with control cells $(\mathrm{p}<$ 0.05 ) or with $S$. aureus supernatant-treated cells ( $\mathrm{p}<$ $0.05)$.

\section{S. aureus supernatant altered chloride efflux, ion and water content}

We next analyzed the time-dependent effect of $2 \% S$. aureus supernatant incubation on cAMP-mediated chloride efflux, and on cytoplasm and secretory granule ion and water content in airway epithelial cells. As shown in figure $4 \mathrm{~A}$, a significant $(\mathrm{p}<0.01)$ time-dependent decrease in chloride efflux was observed after 4 hours of incubation with $2 \% \mathrm{~S}$. aureus supernatant. This decrease became significant after 1 hour (36\%) and reached $70 \%$ after $4 \mathrm{~h}$ incubation. To test whether the effect of $S$. aureus supernatant on chloride secretion was specific to CFTR function alteration, we compared the effect of $S$. aureus supernatant with the effect of a CFTR inhibitor. We observed that incubation of airway glandular cells with the CFTR inhibitor significantly reduced $(\mathrm{p}<0.01)$ the chloride secretion and that this decrease 

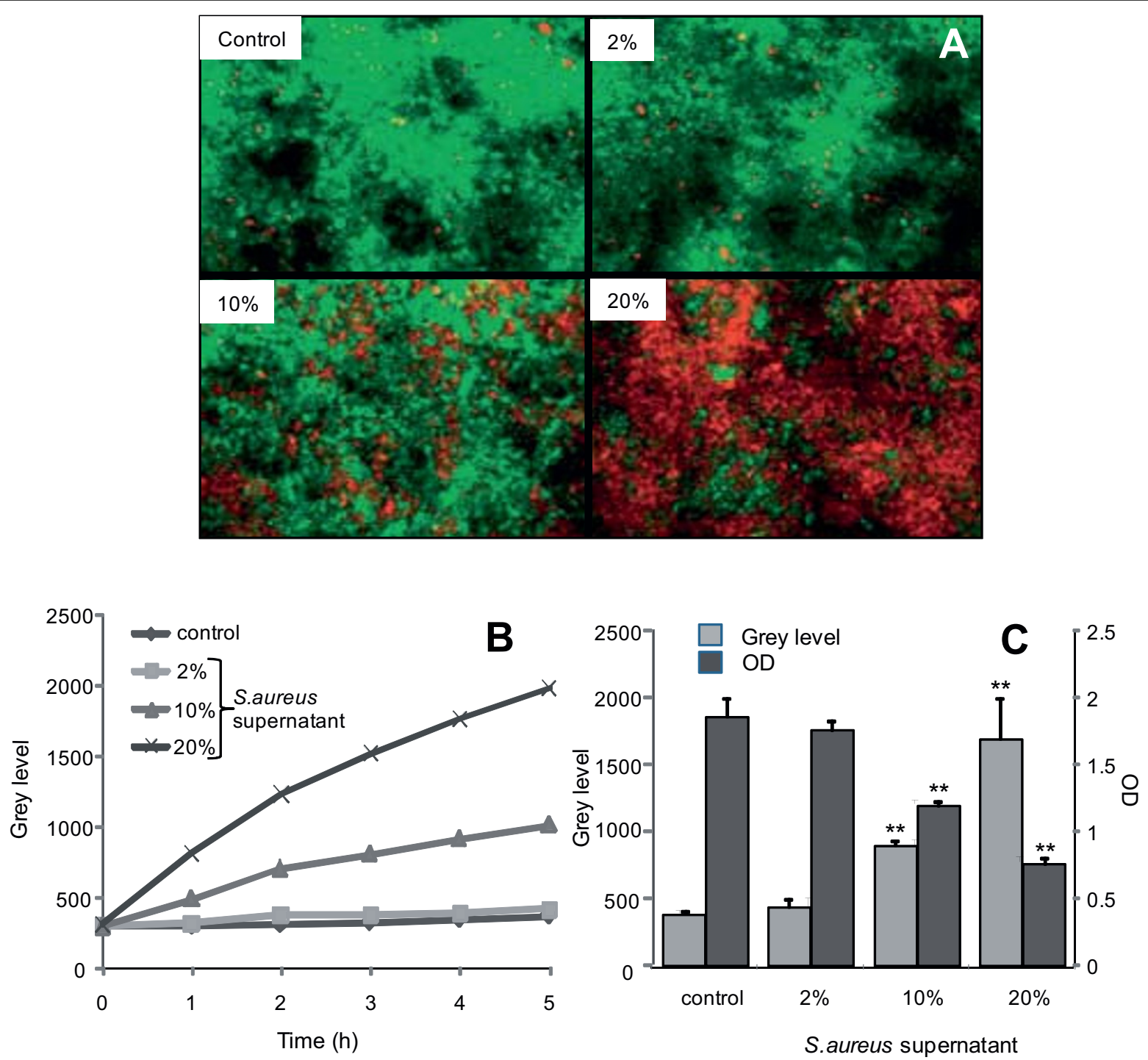

Figure 1 Effect of S. aureus supernatant on cell death. Cell death induced by S. aureus supernatant. (A) Propidium iodide fluorescent probe (red staining) was used to visualize the dead cells and syto 9 fluorescent probe (green staining) was used to visualize all the cells. The number of dead cells was increased in presence of $10 \%$ or $20 \%$ of S. aureus supernatant. (B) Time-dependent increase in fluorescence intensity of propidium iodide in presence of the different concentrations of $S$. aureus supernatant. (C) Fluorescence intensity of the propidium iodide probe after $5 \mathrm{~h}$ of incubation with the different concentrations of $\mathrm{S}$. aureus supernatant. The increase in fluorescence was significant when the cells were incubated with $10 \%$ or $20 \%$ of S. aureus supernatant (*, p $<0.05$; data represent the mean \pm SEM of 3 different experiments). In parallel, the MTT technique showed the number of living cells. The decrease of OD was significant when the cells were incubated with $10 \%$ or $20 \%$ of $S$. aureus supernatant (**, $\mathrm{p}<0.01$; data represent the mean \pm SEM of 8 different wells).

was similar to the decrease observed after $4 \mathrm{~h}$ of incubation with $2 \%$ S. aureus supernatant (figure $4 \mathrm{~B}$ ).

Figure 5 shows the time-dependent effect of $S$. aureus supernatant on the ion concentration and water content measured either in the cell cytoplasm or in the secretory granules. After 2 hours of incubation with S. aureus supernatant, we observed a significant $(\mathrm{p}<0.05)$ increase in sodium concentration and a decrease in sulfur and chloride concentrations in the cytoplasm (figure
5A). In the secretory granules, 1 hour of incubation with $S$. aureus supernatant induced a significant increase $(\mathrm{p}<0.05)$ in sulphur and potassium concentrations and in parallel a significant $(\mathrm{p}<0.05)$ decrease in chloride concentration (figure $5 \mathrm{~B}$ ). The water content was significantly decreased in the cytoplasm (figure $5 \mathrm{C}, \mathrm{p}<0.05$ ) and in the secretory granules (figure $5 \mathrm{D}, \mathrm{p}<0.01$ ) after 2 and 4 hours of incubation with $S$. aureus supernatant, respectively. 

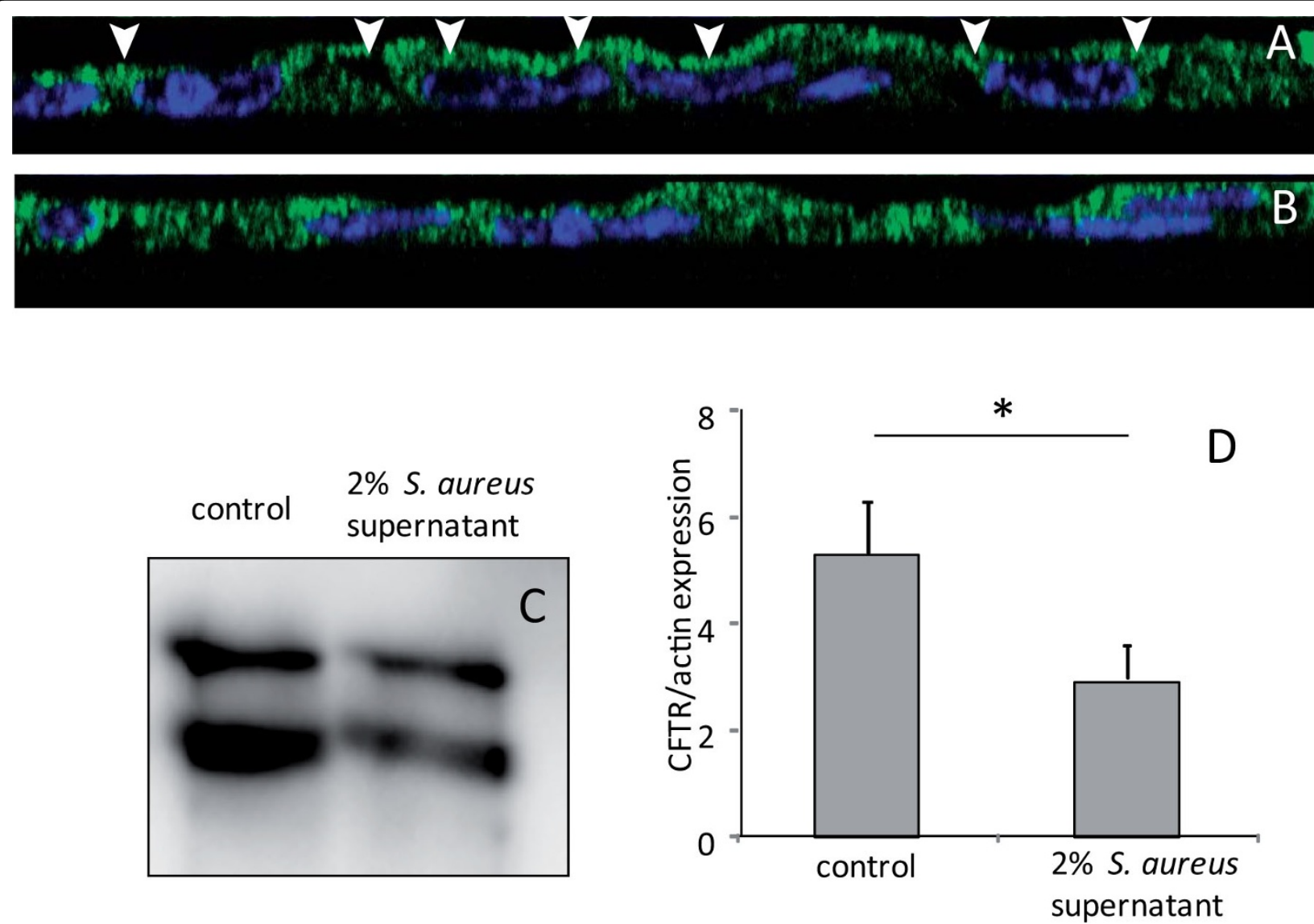

Figure 2 Effect of S. aureus supernatant on CFTR localisation and expression. (A, B) Immunolocalisation of CFTR (green staining) and Dapi nuclei staining (blue) in lateral view of successive z level images. In control cells, we noticed an apical staining of CFTR (arrow heads in A). In $2 \%$ S. aureus supernatant-treated cells (B), the CFTR staining was more diffuse in the cytoplasm. (C) Western blotting analysis of airway glandular cell membrane proteins showed the presence of CFTR in control cells and in fewer amount in cells incubated with 2\%S. aureus supernatant. (D) Quantitative measurement showed a significant $\left(^{*}, p<0.05\right)$ decrease in CFTR expression in cell membranes when cells were incubated with $2 \%$ S. aureus supernatant. Data represent the mean \pm SEM of 5 different experiments.

Sal/FP restores chloride efflux, and ion and water content We analyzed the effect of Sal/FP combination on the chloride efflux and ion and water content in airway epithelial cells. The cells were incubated for $1 \mathrm{~h}$ with $2 \%$ $S$. aureus supernatant and then with Sal/FP for $4 \mathrm{~h}$. As shown in figure 6 , we observed a significant decrease ( $\mathrm{p}$ $<0.01$ ) in chloride efflux after $1 \mathrm{~h}$ incubation with $2 \% S$. aureus supernatant compared to control cells. Incubation of airway epithelial cells with Sal/FP restored the chloride efflux previously decreased by $S$. aureus supernatant. Interestingly, incubation of cells with Sal/FP alone significantly $(\mathrm{p}<0.05)$ enhanced the chloride efflux. We observed that Sal/FP treatment did not significantly modify the cytoplasmic ion and water content (data not shown), but significantly increased the chloride content $(26 \pm 4 \mathrm{mM}$ versus $16 \pm 5 \mathrm{mM} \mathrm{p}<0.05)$ and decreased the sulfur $(31 \pm 2 \mathrm{mM}$ versus $42 \pm 6 \mathrm{mM}, \mathrm{p}<$ $0.01)$ and potassium $(72 \pm 3 \mathrm{mM}$ versus $86 \pm 8 \mathrm{mM}, \mathrm{p}<$
0.05) content in the secretory granules, compared with the $S$. aureus supernatant-treated cells (figure 7).

Sal/FP treatment downregulates $S$. aureus supernatantinduced airway epithelial cytokine release

We investigated whether following the incubation of airway epithelial cells with $S$. aureus supernatant, treatment with Sal/FP was able to modulate cytokine release. Incubation of epithelial cells with $S$. aureus supernatant for $1 \mathrm{~h}$ induced a 12-fold, 21-fold and 21-fold increase $(\mathrm{p}<0.01)$ in the release of IL- 8 , TNF $\alpha$ and IL-6, respectively, compared with control cells (figure $8 \mathrm{~A}, \mathrm{~B}$ and $8 \mathrm{C})$. Interestingly, following $1 \mathrm{~h}$ incubation of epithelial cells with $S$. aureus supernatant, a $4 \mathrm{~h} \mathrm{Sal} / \mathrm{FP}$ treatment significantly $(\mathrm{p}<0.01)$ reduced the $S$. aureus supernatant-induced IL-8 release (28\%, figure $8 \mathrm{~A})$. Sal/FP treatment also decreased $(\mathrm{p}<0.05)$ S. aureus supernatantinduced $\mathrm{TNF} \alpha$ secretion (50\%, figure $8 \mathrm{~B}$ ) whereas it had no effect on $S$. aureus supernatant-induced IL-6 release (figure 8C). 


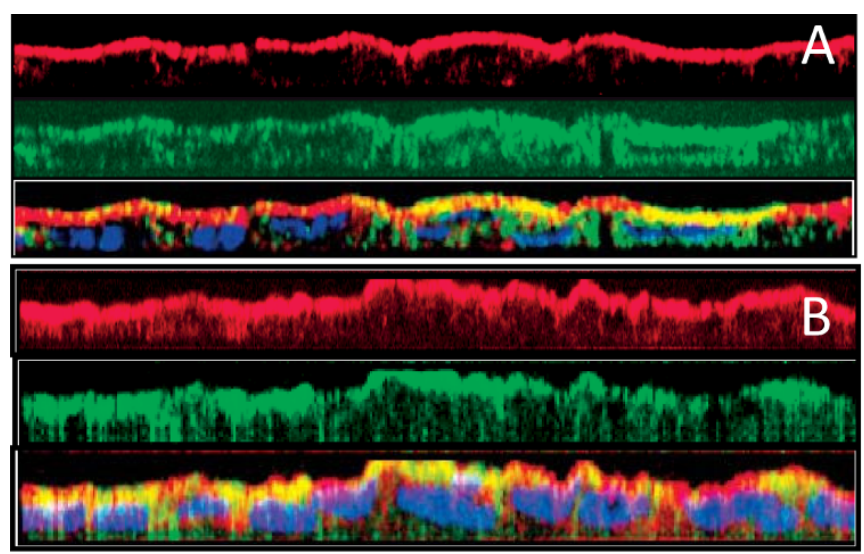

control

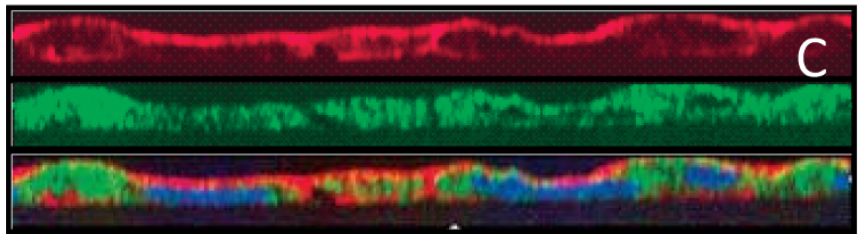

S. aureus

supernatant



\section{S.aureus}

supernatant

+ Sal/FP



Figure 3 Co-localisation by immunofluorescence of CFTR and actin. (A) The pattern of CFTR (green staining) and actin (red staining) stainings was essentially apical in control cells as well as in cells treated with Sal/FP (B). (C) The incubation of cells with S. aureus supernatant induced alteration of the localisation of CFTR that appeared to be cytoplasmic, in parallel with a disorganization of the actin network. (D) Treatment of S. aureus supernatant pre-incubated cells with Sal/FP restored CFTR and actin apical stainings. (E) Quantification of the colocalisation of CFTR and actin showed that $2 \%$ S. aureus supernatant decreased the co-localisation index compared to the index in control cells, but the difference was not significant; the treatment with Sal/FP alone or after S. aureus supernatant incubation significantly enhanced the colocalisation of the 2 proteins compared with control or with $S$. aureus supernatant-treated cells $\left.{ }^{*}, p<0.05\right)$. Data represent the mean \pm SEM of 3 different experiments. 

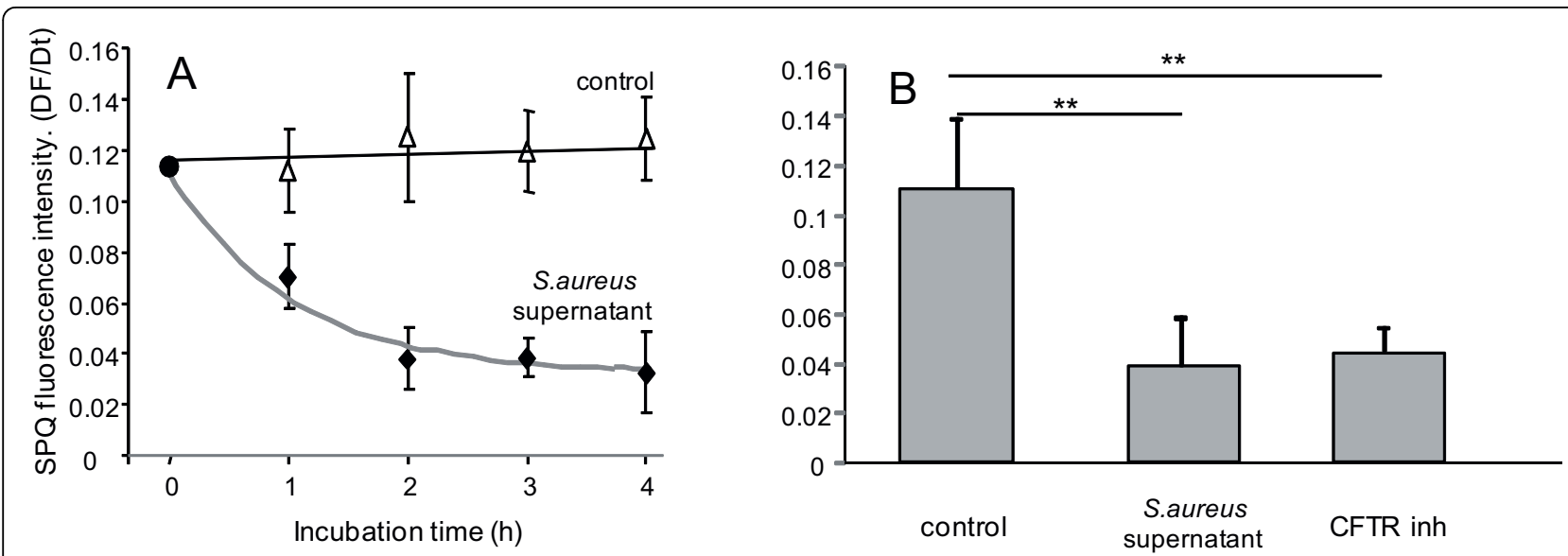

Figure 4 Effect of S. aureus supernatant on cAMP-mediated chloride efflux. (A) Time-dependent effect of S. aureus supernatant incubation on cAMP-mediated chloride efflux. We observed a significant $(p<0.01)$ time-dependent decrease in chloride efflux when cells were incubated with $2 \%$ S. aureus supernatant. This decrease became significant as soon as after 1 hour of incubation with 2\% VF. (B) CFTR inh172 significantly decreased the chloride efflux compared to control $(* *, p<0.01)$ and this decrease was similar to the decrease induced by $S$. aureus supernatant. Data represent the mean \pm SEM of 3 different experiments.

\section{Sal/FP treatment downregulates S. aureus supernatant-} induced airway epithelial cytokine mRNA levels

We next determined by semi-quantitative RT-PCR the effects of Sal/FP on $S$. aureus supernatant-induced IL-8 and TNF $\alpha$ mRNA levels. As shown in figure 9, incubation of epithelial cells with $S$. aureus supernatant for $1 \mathrm{~h}$ induced a 5 -fold and a 3.5 -fold increase $(\mathrm{p}<0.05)$ in IL8 (figure 9A) and TNF $\alpha$ mRNA (figure 9B) levels, respectively, compared with control cells. Following $1 \mathrm{~h}$ incubation of epithelial cells with $S$. aureus supernatant, Sal/FP treatment for $4 \mathrm{~h}$ significantly $(\mathrm{p}<0.05)$ reduced $S$. aureus supernatant-induced IL-8 mRNA level (36\%, Figure 9A), but had no significant effect on TNF $\alpha$ (figure 9B).

\section{Discussion}

In the present study, we show that the treatment of airway epithelial cells with a combination of a corticosteroid and a long-acting $\beta_{2} \mathrm{AR}$ agonist, after incubation with $S$. aureus supernatant, restores the function of airway glandular epithelial cells previously altered by bacterial VF. We pre-incubated airway glandular cells with crude extracts from $S$. aureus, which contain many types of VF including toxins and proteases. The main purpose of the present work was to evaluate the effect of drugs able to restore the airway epithelium functions rather than to pinpoint which bacterial factors are responsible for the alterations of these functions. We have chosen to test the effect of the combination of Sal and FP since it has been previously demonstrated that this combination induced a marked increase in the nuclear glucocorticoid receptor expression in airway epithelial cells and a significant synergistic decrease of
IL-8, IL-6 and TNF- $\alpha$, at both transcriptional and translational levels [12].

It has been suggested by Nadel and Borson [29] that ion transport in airways can be severely altered during infection and inflammation. Indeed, Swiatecka-Urban et al [30] reported that a cell-free filtrate of Pseudomonas aeruginosa reduced CFTR-mediated transepithelial chloride secretion by inhibiting the endocytic recycling of CFTR. Our results are in accordance with recent studies which reported that recombinant sphingomyelinase $\mathrm{C}$ (membrane-damaging virulence factor originally called $\beta$-hemolysin) from $S$. aureus strongly inhibited CFTRdependent chloride current and that the cytoskeleton was remodelled through the acid sphingomyelinase/ceramide pathway [31,32]. Moreover, it has been previously demonstrated that actin cytoskeleton organization was required for cAMP-dependent activation of CFTR $[33,34]$. It is likely that the decreased activity of CFTR observed in presence of $S$. aureus supernatant could be related to the disruption of the actin cytoskeleton, leading to delocalisation and consequently inhibition of CFTR as demonstrated here by immunofluorescence. Glucocorticoids have been shown to increase the stability of actin filaments, increase actin polymerization, activate cytoskeleton-associated kinases and stabilize actin filaments against disruption by injury [35]. We hypothesize that incubation of $S$. aureus supernatanttreated cells with FP might prevent actin cytoskeleton degradation, leading to the recovery of functional CFTR chloride channels. In addition to the effect of FP on CFTR function, Taouil et al [11] previously demonstrated that the $\beta 2$-AR agonist Sal was able to increase CFTR expression in human airway epithelial cells. It is 


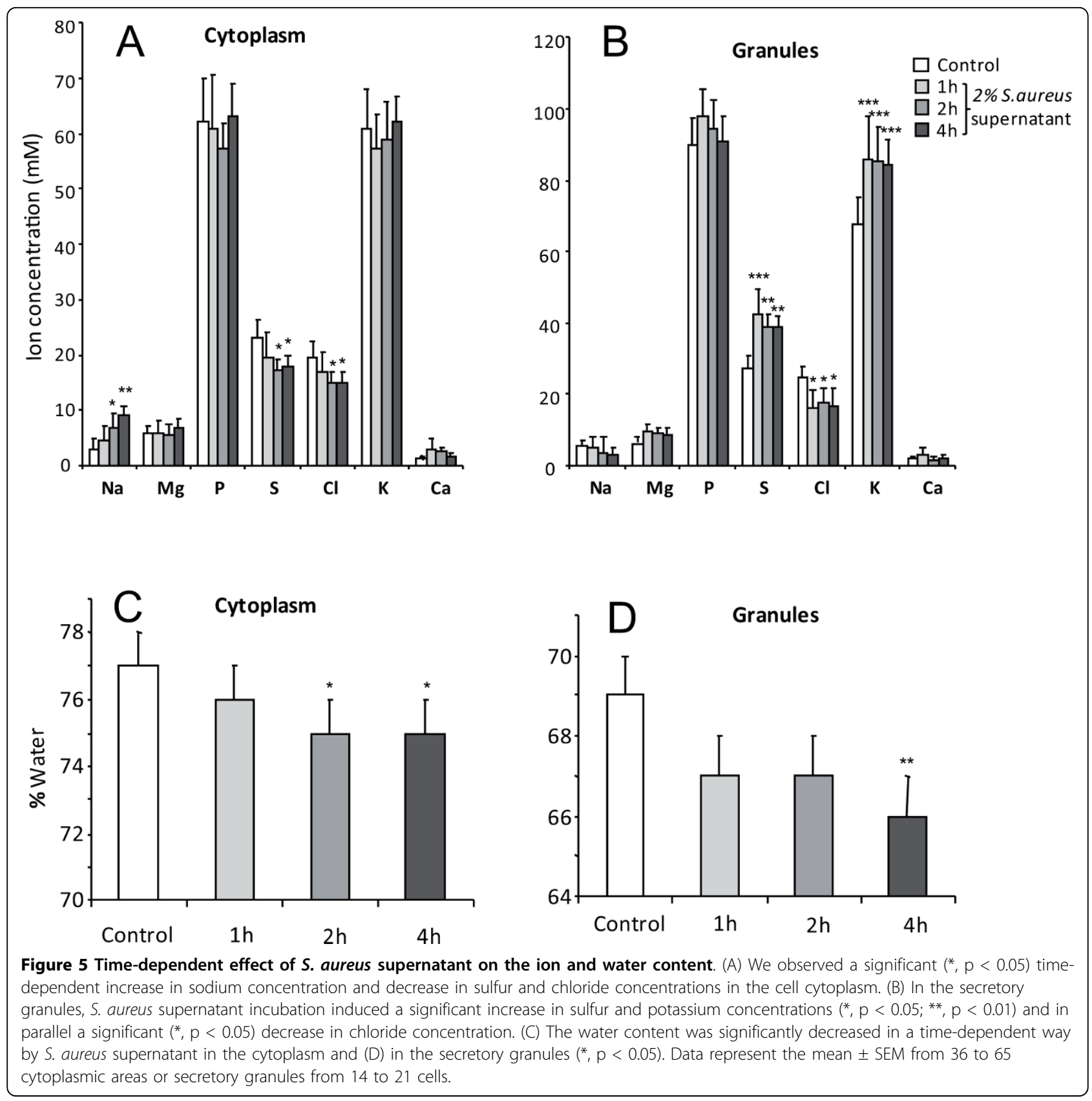

also known that actin can interact directly or indirectly with epithelial ion channels through scaffolding proteins (NHERFs) or actin-binding proteins. Ganeshan et al [36] demonstrated that CFTR surface expression and chloride current were decreased by inhibitors of actin polymerisation. Together, these data indicate that modulation of the actin cytoskeleton may be a mechanism for regulating the CFTR function. Our findings also support the hypothesis that infection alters airway epithelial ion transport and that combination treatment with glucocorticoids and long-acting $\beta 2$-AR agonists may be helpful in restoring normal epithelial ion transport function.

At the cytoplasmic level, we observed that $S$. aureus supernatant induced an increase in sodium concentration, which reflected an inability to regulate sodium absorption, likely related to a reduced CFTR function at the apical membrane. The reduced CFTR function is likely linked to CFTR delocalisation as assessed by immunocytochemistry. As a biological significance, one can compare this 3 -fold increase in sodium 


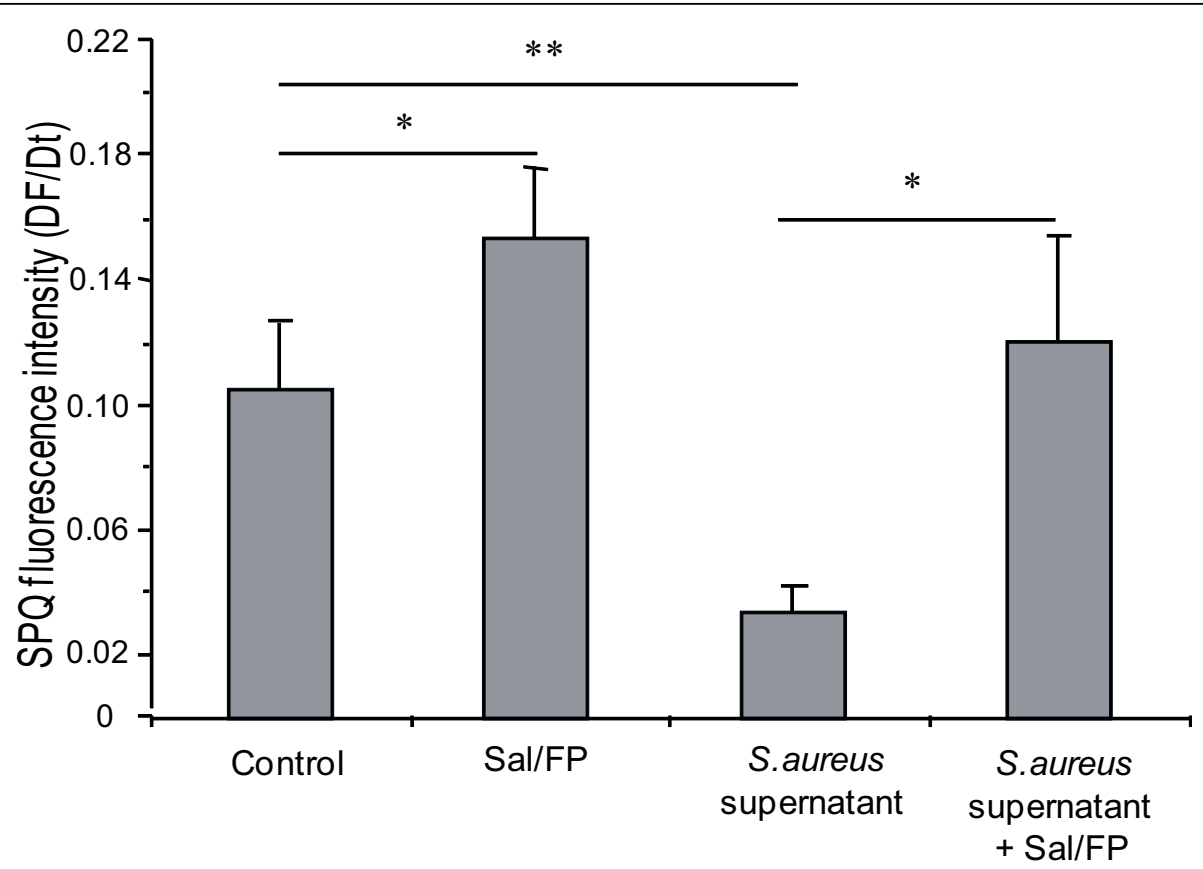

Figure 6 Effect of Sal/FP treatment on the chloride efflux. A significant decrease $\left({ }^{*}, p<0.05\right)$ in chloride efflux after $1 \mathrm{~h}$ incubation with $2 \%$ S. aureus supernatant was observed. The treatment of airway epithelial cells with Sal/FP significantly $\left.{ }^{*}, p<0.05\right)$ restored the chloride efflux previously decreased by $S$. aureus supernatant. Data represent the mean \pm SEM of 3 different experiments.



Figure 7 Effect of Sal/FP treatment on the ion content. We observed that Sal/FP treatment significantly increased the chloride content $\left(^{*}, \mathrm{p}\right.$ $<0.05$ ) and decreased the sulfur and potassium content ( ${ }^{* *}, p<0.01$ and ${ }^{*}, p<0.05$, respectively) in the intra-cytoplasmic secretory granules, compared to S. aureus supernatant-treated cells. Data represent the mean \pm SEM from 36 to 65 cytoplasmic areas or secretory granules from 14 to 21 cells. 




concentration to the 5-fold increase that we observed when comparing sodium content in secretory granules from non-CF and CF cells [37]. This increase was accompanied by a decrease in cytoplasmic chloride concentration, despite the defect of cAMP CFTR-mediated chloride secretion assessed by fluorescence microscopy. Since there was an increase in cytoplasmic calcium concentration, we can therefore hypothesize that calcium activated chloride channels $(\mathrm{CaCC})$ could be involved. Increased cytosolic calcium in host cells can be induced by bacterial toxins [38]. We can therefore speculate that $S$. aureus supernatant may be responsible for the timedependent increase in calcium concentration, followed by the upregulation of $\mathrm{CaCC}$ and, as a consequence, an activation of calcium-dependent chloride conductance. The increase of sulfur content in the secretory granules
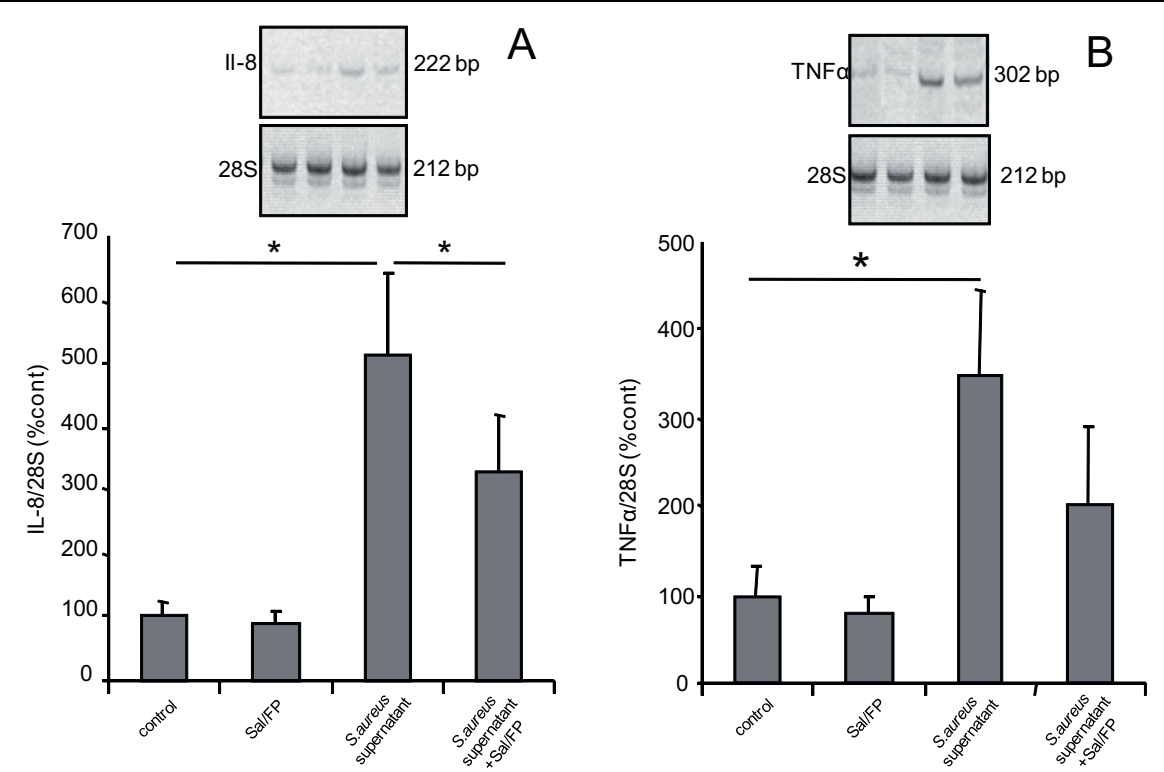

Figure 9 Semi quantitative RT-PCR analysis of IL-8 and TNF $\alpha$ mRNA levels. The incubation with S. aureus supernatant for $1 \mathrm{~h}$ increased significantly (*, $\mathrm{p}<0.05) \mathrm{IL}-8$ and TNF $\alpha$ mRNA levels compared to control condition (A and B, respectively). When the incubation of $S$. aureus supernatant for $1 \mathrm{~h}$ was followed by treatment with Sal/FP for $4 \mathrm{~h}$, S. aureus supernatant-induced IL-8 (A) mRNA level was significantly ${ }^{*}$, $\mathrm{p}<$ 0.05) reduced, but no significant effect was observed for TNF $\alpha$. Results are normalized to the $28 \mathrm{~S}$ level and are expressed as mean \pm SEM of 8 independent experiments performed in duplicate. 
after incubation with $S$. aureus supernatant could be associated with increasing mucin synthesis observed in previous studies [39]. All these data suggest a general mechanism by which epithelial glandular cells respond to the presence of bacteria.

In a previous study [12], we have demonstrated that $S$. aureus supernatant induced an upregulation of proinflammatory molecules such as IL-8, IL-6 and TNF $\alpha$ at mRNA and protein levels. We also reported that the pre-incubation of airway cells with the combination of Sal and FP had a beneficial effect in downregulating inflammatory cytokines following $S$. aureus infection. Pro-inflammatory mediator levels are markedly increased in induced sputum of patients with COPD [40]. The concentration of these mediators are further increased during acute exacerbations [41] and a correlation has been reported between pro-inflammatory mediator concentrations and the bacterial colony count in sputum [42]. In our present study, we confirm that $S$. aureus supernatant, even at low concentration, induces a marked increase in IL-6, IL- 8 and TNF $\alpha$ release by airway glandular cells. Elevated TNF $\alpha$ levels are associated with increased IL- 8 levels, and TNF $\alpha$ is a major inducer of IL-8 expression in lung epithelial cells [43]. In addition, TNFa which is increased by $S$. aureus supernatant might also act on the regulation of CFTR function. Indeed, it has been reported that this cytokine was able to modulate ion secretion in different kind of epithelia. Although it increases ion secretion in human intestinal epithelium [44], TNF $\alpha$ attenuates $\beta$ agonistevoked increase in chloride secretion across canine tracheal epithelium [45]. Using epithelial cells expressing wild-type CFTR or mutant CFTR lacking its PDZ-interacting domain, Dudez et al [46] have demonstrated that TNF $\alpha$ increased the amount of wild-type CFTR but not mutant CFTR in detergent-resistant membrane microdomains in which CFTR interacts with TNF $\alpha$ receptor-1 signaling cascade to regulate cytokine expression. Alteration of the formation of this complex may provide an explanation to some dysfunction of epithelial cell lacking a functional CFTR as observed in our study or in CF. Some studies have shown that $\beta 2$-AR agonists, when given on their own, increased IL-8 release, but a strong synergistic inhibitory interaction between $\beta 2$-agonists and steroids on IL- 8 production has been described [47]. Steroids increase $\beta 2$-receptor synthesis and $\beta 2$-agonists prime glucocorticoid receptors for steroid-dependent activation and enhance nuclear translocation [48]. Interestingly, post-treatment with the combination of Sal/FP significantly reduced the IL- 8 and TNF $\alpha$ level compared with levels in $S$. aureus supernatant-treated cells.

\section{Conclusion}

The present data demonstrate that bacterial infection may lead to severe disruption of ion transport across the airway epithelium and to associated secretory granule dehydration, which may lead to defective mucociliary clearance in the airways, as previously shown by Puchelle et al who reported a relationship between the degree of infection and the rheological and transport properties of airway mucus in CF [8]. Together, our data indicate that abnormal mucus and upregulation of inflammatory cytokines associated with defective ion transport could benefit from treatment with drugs that could restore a normal function of secretory airway cells.

\section{Acknowledgements}

FD was supported by association Vaincre La Mucoviscidose. This work was supported by Vaincre La Mucoviscidose and GlaxoSmithKline grants.

\section{Author details}

${ }^{1}$ INSERM, U903, Reims, F-51092, France. ${ }^{2}$ INSERM, U926, Reims, F-51097, France. ${ }^{3}$ Univ Reims Champagne Ardenne, IFR53, Reims, F-51097, France. ${ }^{4} \mathrm{CHU}$ Reims, Laboratoire Pol Bouin, Reims, F-51092, France. ${ }^{5}$ GlaxoSmithKlein Research and Development, Middlesex, UK.

\section{Authors' contributions}

JMZ developed image analysis techniques, drafted the manuscript and participated in its design and coordination. FD carried out X-ray microanalysis and water content measurement. FT performed ELISA and RTPCR for cytokine analysis. CK participated in cell culture and immunocytochemistry. BNR performed western blot analysis. JM, GB, MJ, CC and PB conceived the study, participated in its design and coordination and helped to draft the manuscript. All authors read and approved the final manuscript.

\section{Competing interests}

JMZ has received research grants from GSK (UK) to support work carried out in the laboratory. MJ is employed by GlaxoSmithKline who markets Seretide, a combination of a long-acting beta-agonist (salmeterol) and a corticosteroid (fluticasone propionate). FD, FT, BNR, CK, JM, GB, CC, PB do not have a financial relationship with a commercial entity that has an interest in the subject of this manuscript.

\section{Received: 29 May 2009}

Accepted: 20 January 2010 Published: 20 January 2010

\section{References}

1. Lowy FD: Staphylococcus aureus infections. N Engl J Med 1998, 339:520532.

2. Burns JL, Emerson J, Stapp JR, Yim DL, Krzewinski J, Louden L, Ramsey BW, Clausen CR: Microbiology of sputum from patients at cystic fibrosis centers in the United States. Clin Infect Dis 1998, 27:158-163.

3. Dinges MM, Orwin PM, Schlievert PM: Exotoxins of Staphylococcus aureus. Clin Microbiol Rev 2000, 13:16-34.

4. Dupuit F, Kalin N, Brezillon S, Hinnrasky J, Tummler B, Puchelle E: CFTR and differentiation markers expression in non-CF and delta $F 508$ homozygous CF nasal epithelium. J Clin Invest 1995, 96:1601-1611.

5. Rogers DF: Physiology of airway mucus secretion and pathophysiology of hypersecretion. Respir Care 2007, 52:1134-1146.

6. Aikawa T, Shimura S, Sasaki H, Takishima T, Yaegashi H, Takahashi T: Morphometric analysis of intraluminal mucus in airways in chronic obstructive pulmonary disease. Am Rev Respir Dis 1989, 140:477-482. 
7. Galabert C, Jacquot J, Zahm JM, Puchelle E: Relationships between the lipid content and the rheological properties of airway secretions in cystic fibrosis. Clin Chim Acta 1987, 164:139-149.

8. Puchelle E, Jacquot J, Beck G, Zahm JM, Galabert C: Rheological and transport properties of airway secretions in cystic fibrosis-relationships with the degree of infection and severity of the disease. Eur J Clin Invest 1985, 15:389-394.

9. Voynow JA, Rubin BK: Mucins, mucus, and sputum. Chest 2009, 135:505512.

10. Coraux C, Kileztky C, Polette M, Hinnrasky J, Zahm JM, Devillier P, De BS, Puchelle E: Airway epithelial integrity is protected by a long-acting beta2-adrenergic receptor agonist. Am J Respir Cell Mol Biol 2004, 30:605612.

11. Taouil K, Hinnrasky J, Hologne C, Corlieu P, Klossek JM, Puchelle E: Stimulation of beta 2-adrenergic receptor increases cystic fibrosis transmembrane conductance regulator expression in human airway epithelial cells through a cAMP/protein kinase A-independent pathway. J Biol Chem 2003, 278:17320-17327.

12. Fragaki K, Kileztky C, Trentesaux C, Zahm JM, Bajolet O, Johnson M, Puchelle E: Downregulation by a long-acting beta2-adrenergic receptor agonist and corticosteroid of Staphylococcus aureus-induced airway epithelial inflammatory mediator production. Am J Physiol Lung Cell Mol Physiol 2006, 291:L11-L18.

13. Wedzicha JA, Calverley PM, Seemungal TA, Hagan G, Ansari Z, Stockley RA: The prevention of chronic obstructive pulmonary disease exacerbations by salmeterol/fluticasone propionate or tiotropium bromide. Am J Respir Crit Care Med 2008, 177:19-26.

14. Boyer L, Doye A, Rolando M, Flatau G, Munro P, Gounon P, Clement R, Pulcini C, Popoff MR, Mettouchi A, Landraud L, Dussurget O, Lemichez E: Induction of transient macroapertures in endothelial cells through RhoA inhibition by Staphylococcus aureus factors. J Cell Biol 2006, 173:809-819.

15. Ganeshan R, Nowotarski K, Di A, Nelson DJ, Kirk KL: CFTR surface expression and chloride currents are decreased by inhibitors of N-WASP and actin polymerization. Biochim Biophys Acta 2007, 1773:192-200.

16. Dowling RB, Johnson M, Cole PJ, Wilson R: Effect of fluticasone propionate and salmeterol on Pseudomonas aeruginosa infection of the respiratory mucosa in vitro. Eur Respir J 1999, 14:363-369.

17. Nakagawa NK, Franchini ML, Driusso P, de Oliveira LR, Saldiva PH, LorenziFilho G: Mucociliary clearance is impaired in acutely ill patients 1 . Chest 2005, 128:2772-2777.

18. Dowling RB, Rayner CF, Rutman A, Jackson AD, Kanthakumar K, Dewar A, Taylor GW, Cole PJ, Johnson M, Wilson R: Effect of salmeterol on Pseudomonas aeruginosa infection of respiratory mucosa. Am J Respir Crit Care Med 1997, 155:327-336.

19. Escotte S, Tabary O, Dusser D, Majer-Teboul C, Puchelle E, Jacquot J: Fluticasone reduces IL- 6 and IL-8 production of cystic fibrosis bronchial epithelial cells via IKK-beta kinase pathway. Eur Respir J 2003, 21:574-581.

20. Merten MD, Kammouni W, Renaud W, Birg F, Mattei MG, Figarella C: A transformed human tracheal gland cell line, MM- 39 , that retains serous secretory functions. Am J Respir Cell Mol Biol 1996, 15:520-528.

21. Chevillard M, Hinnrasky J, Pierrot D, Zahm JM, Klossek JM, Puchelle E: Differentiation of human surface upper airway epithelial cells in primary culture on a floating collagen gel. Epithelial Cell Biol 1993, 2:17-25.

22. Hata K, Yoshimoto T, Mizuguchi J: CD40 ligand rescues inhibitor of differentiation 3-mediated G1 arrest induced by anti-IgM in WEHI-231 B lymphoma cells. J Immunol 2004, 173:2453-2461.

23. European Working Group on CFTR Expression. http://pen2.igc.gulbenkian. $\mathrm{pt} / \mathrm{cftr} / \mathrm{vr} / \mathrm{index} . \mathrm{html}$.

24. Bonnet $\mathrm{N}$, Zahm JM: Analysis of image sequences in fluorescence videomicroscopy of stationary objects. Cytometry 1998, 31:217-228

25. Thiagarajah JR, Song Y, Haggie PM, Verkman AS: A small molecule CFTR inhibitor produces cystic fibrosis-like submucosal gland fluid secretions in normal airways. FASEB J 2004, 18:875-877.

26. Baconnais S, Zahm J, Kilian L, Bonhomme P, Gobillard D, Perchet A, Puchelle $E$, Balossier $G$ : $X$-ray microanalysis of native airway surface liquid collected by cryotechnique. J Microsc 1998, 191:311-319.
27. Zierold K: Heavy metal cytotoxicity studied by electron probe X-ray microanalysis of cultured rat hepatocytes. Toxicol In Vitro 2000, 14:557563.

28. Chasan B, Geisse NA, Pedatella K, Wooster DG, Teintze M, Carattino MD, Goldmann WH, Cantiello HF: Evidence for direct interaction between actin and the cystic fibrosis transmembrane conductance regulator. Eur Biophys J 2002, 30:617-624.

29. Dohrman A, Miyata S, Gallup M, Li JD, Chapelin C, Coste A, Escudier E, Nadel J, Basbaum C: Mucin gene (MUC 2 and MUC 5AC) upregulation by Gram-positive and Gram-negative bacteria. Biochim Biophys Acta 1998, 1406:251-259.

30. Swiatecka-Urban A, Moreau-Marquis S, MacEachran DP, Connolly JP, Stanton CR, Su JR, Barnaby R, OToole GA, Stanton BA: Pseudomonas aeruginosa inhibits endocytic recycling of CFTR in polarized human airway epithelial cells. Am J Physiol Cell Physiol 2006, 290:C862-C872.

31. Ramu Y, Xu Y, Lu Z: Inhibition of CFTR Cl- channel function caused by enzymatic hydrolysis of sphingomyelin. Proc Natl Acad Sci USA 2007, 104:6448-6453.

32. Zeidan YH, Jenkins RW, Hannun YA: Remodeling of cellular cytoskeleton by the acid sphingomyelinase/ceramide pathway. J Cell Biol 2008, 181:335-350.

33. Prat AG, Cunningham CC, Jackson GR Jr, Borkan SC, Wang Y, Ausiello DA, Cantiello HF: Actin filament organization is required for proper CAMPdependent activation of CFTR. Am J Physiol 1999, 277:C1160-C1169.

34. Mazzochi C, Benos DJ, Smith PR: Interaction of epithelial ion channels with the actin-based cytoskeleton. Am J Physiol Renal Physiol 2006, 291: F1113-F1122.

35. Ransom RF, Lam NG, Hallett MA, Atkinson SJ, Smoyer WE: Glucocorticoids protect and enhance recovery of cultured murine podocytes via actin filament stabilization. Kidney Int 2005, 68:2473-2483.

36. Ganeshan R, Nowotarski K, Di A, Nelson DJ, Kirk KL: CFTR surface expression and chloride currents are decreased by inhibitors of N-WASP and actin polymerization. Biochim Biophys Acta 2007, 1773:192-200.

37. Baconnais S, Delavoie F, Zahm JM, Milliot M, Terryn C, Castillon N, Banchet V, Michel J, Danos O, Merten M, Chinet T, Zierold K, Bonnet N, Puchelle E, Balossier G: Abnormal ion content, hydration and granule expansion of the secretory granules from cystic fibrosis airway glandular cells. Exp Cell Res 2005, 309:296-304.

38. Tran Van Nhieu G, Clair C, Grompone G, Sansonetti P: Calcium signalling during cell interactions with bacterial pathogens. Biololy of the Cell 2004, 96:93-101.

39. Dohrman A, Miyata S, Gallup M, Li JD, Chapelin C, Coste A, Escudier E, Nadel J, Basbaum C: Mucin gene (MUC 2 and MUC 5AC) upregulation by Gram-positive and Gram-negative bacteria. Biochim Biophys Acta 1998, 1406:251-259.

40. Keatings VM, Collins PD, Scott DM, Barnes PJ: Differences in interleukin-8 and tumor necrosis factor-alpha in induced sputum from patients with chronic obstructive pulmonary disease or asthma. Am J Respir Crit Care Med 1996, 153:530-534.

41. Aaron SD, Angel JB, Lunau M, Wright K, Fex C, Le Saux N, Dales RE: Granulocyte inflammatory markers and airway infection during acute exacerbation of chronic obstructive pulmonary disease. Am J Respir Crit Care Med 2001, 163:349-355.

42. Hill AT, Campbell EJ, Hill SL, Bayley DL, Stockley RA: Association between airway bacterial load and markers of airway inflammation in patients with stable chronic bronchitis. Am J Med 2000, 109:288-295.

43. Chandru H, Boggaram V: The role of sphingosine 1-phosphate in the TNF-alpha induction of IL-8 gene expression in lung epithelial cells. Gene 2007, 391:150-160.

44. Bode H, Schmitz H, Fromm M, Scholz P, Riecken EO, Schulzke JD: IL-1 beta and TNF-alpha, but not IFN-alpha, IFN-gamma, IL-6 or IL-8, are secretory mediators in human distal colon. Cytokine 1998, 10:457-465.

45. Satoh M, Sasaki T, Shimura S, Sasaki H, Takishima T: Tumor necrosis factor attenuates beta agonist-evoked $\mathrm{Cl}$ - secretion in canine tracheal epithelium. Respir Physiol 1991, 84:379-387.

46. Dudez T, Borot F, Huang S, Kwak BR, Bacchetta M, Ollero M, Stanton BA, Chanson M: CFTR in a lipid raft-TNFR1 complex modulates gap 
junctional intercellular communication and IL-8 secretion. Biochim Biophys Acta 2008, 1783:779-788.

47. Pang L, Knox AJ: Synergistic inhibition by beta(2)-agonists and corticosteroids on tumor necrosis factor-alpha-induced interleukin-8 release from cultured human airway smooth-muscle cells. Am J Respir Cell Mol Biol 2000, 23:79-85

48. Johnson M: Corticosteroids: potential beta2-agonist and anticholinergic interactions in chronic obstructive pulmonary disease. Proc Am Thorac Soc 2005, 2:320-325.

doi:10.1186/1465-9921-11-6

Cite this article as: Zahm et al:: Long acting $\beta 2$-agonist and

corticosteroid restore airway glandular cell function altered by bacterial supernatant. Respiratory Research 2010 11:6.

Publish with Biomed Central and every scientist can read your work free of charge

"BioMed Central will be the most significant development for disseminating the results of biomedical research in our lifetime." Sir Paul Nurse, Cancer Research UK

Your research papers will be:

- available free of charge to the entire biomedical community

- peer reviewed and published immediately upon acceptance

- cited in PubMed and archived on PubMed Central

- yours - you keep the copyright 